Saudi Journal of Oral and Dental Research

Abbreviated Key Title: Saudi J Oral Dent Res

ISSN 2518-1300 (Print) |ISSN 2518-1297 (Online)

Scholars Middle East Publishers, Dubai, United Arab Emirates

Journal homepage: https://saudijournals.com/sjodr

\title{
Preference of Intracanal Medicaments in Practicing Endodontists: A Qualitative Research
}

Dr. Thouseef $\mathrm{Ch}^{1 *}$, Dr. Jyothsna Manchikalapudi, BDS ${ }^{2}$, Dr. Mariam Omer Bin Hamza, MDS ${ }^{3}$, Dr. Alankrutha Gangasani, B.D.S ${ }^{4}$, Dr. Rajwinder Singh Brar ${ }^{5}$, Dr. Prashik Parvekar, PhD Scholar ${ }^{6}$

${ }^{1}$ Senior Lecture, Department of Conservative Dentistry \& Endodntics, Malabar Dental College \& Research Center, Malappuram, Kerala

${ }^{2}$ Panineeya Mahavidyalaya Institute of Dental Sciences and Research Center, Hyderabad, Telangana, India

${ }^{3}$ Endodontics Registrar Endodontist Alkharj Armed Forces Hospital Saudi Arabia

${ }^{4}$ Panineeya Mahavidyalaya Institute of Dental Sciences and Research Center, Hyderabad, Telangana, India

${ }^{5}$ Department of Orthodontics, Senior lecturer at Rayat Bahra dental college SAS Nagar, Punjab, India

${ }^{6}$ Department of Conservative Dentistry \& Endodontics, Pacific academy of higher education and research university, Udaipur

DOI: $10.36348 /$ sjodr.2020.v05i05.001 | Received: 23.04.2020 | Accepted: 01.05.2020 | Published: 05.05.2020

*Corresponding author: Dr. Thouseef $\mathrm{Ch}$

Abstract

Aim of the study: The purpose of the study was to assess the preferences of intra-canal medicaments of Endodontists and their method of delivery into the root canal system: Methodology: A questionnaire survey was conducted which was observational and descriptive, amongst 56 Endodontists over a period of 6 months. The questions were based on method of delivery of Intra-canal medicaments, as well as preference for these medicaments. Survey also asked the respondents about the importance of using ICMs in various endodontic conditions. Questions were also put forward that if they used different ICMs for different endodontic issues or prefer the same in all the cases. Results: While the vast majority of endodontist users in this scenario (87.5\%) chose Non-setting Calcium Hydroxide, some of them (10\%) used Formocresol. Others used triple antibiotic paste (2.5\%). All endodontists (100\%) used ICMs in cases of necrotic pulp with periapical lesions. Most respondents $(48.8 \%)$ were in the habit of using injecting syringes to insert paste-based ICMs. Maximum using injecting syringes (48.8\%), followed by Lentulo spirals (23.8\%). Conclusion: Elimination of microbial contamination from the root canal system is a prerequisite to the successful outcome of root canal treatment and ICMs certainly help in this regard. However, all of the currently available antimicrobial materials for root canal irrigation and medication have limitations, and the search continues for the ideal irrigant and intra-appointment medicament.

Keywords: Intracanal medicaments, Endodontic treatment, healing.

Copyright @ 2020: This is an open-access article distributed under the terms of the Creative Commons Attribution license which permits unrestricted use, distribution, and reproduction in any medium for non-commercial use (NonCommercial, or CC-BY-NC) provided the original author and source are credited.

\section{INTRODUCTION}

A successful root canal treatment (RCT) must involve the complete elimination of microorganisms, which can be mainly achieved by efficient cleaning and shaping $(C \& S)$ of the root canal system. However, the role of intra-canal medications (ICMs) cannot be ignored. Traditionally, it is believed that ICMs have an adjunct impact on the complete disinfection of root canals. Due to the complexity of the root canal morphology, hand and rotary files cannot clean areas such as the isthmuses, lateral canals, and dentinal tubules. In such cases, effective irrigation, as well as the use of ICMs, is essential. In addition, ICMs may indirectly contribute to the healing of the affected periapical tissues [1]. The ICMs may be used for a number of purposes; for instance, to reduce or prevent inter-appointment pain and to provide a supplementary coronal seal in temporary restorations[2]. The main rational behind intracanal medicament is to kill the bacteria inside the root canal and to avert reinfection. In absence of nutrients, the bacteria remain after obturation in root canal may die. If they survive, they may flourish. The bacteria which remain in dentinal tubules cannot be removed through chemo mechanical preparation. If the root canal is not dressed properly with antiseptic medicaments between the visits, the residual bacteria may increase in same number as it was in the starting stage of treatment. Thus, the use of effective intracanal medication for disinfection of root canal is necessitated [3]. Medicament with long effect and least irritated to peri-radicular tissue has to be introduced to infiltrate the dentinal tubule eliminating bacteria when time does not allow completing the treatment at one visit. As the effect of intracanal 
medicaments is longer than irrigants, it is generally recommended to fill the root canal between appointments with intracanal medicaments [4]. The medicaments are required to be active in the presence of protein derivatives and should not limit its own diffusion by precipitation of albumin when tissue fluid may enter through apical foramen. It should also be easily diffusible to reach organisms placed in the minor irregularities of the canal. Diffusion of the agent in an apical direction is obviously suggested [5]. While selecting intracanal dressings, microbial composition of infected root canals is an important factor. These intracanal medicaments (Table 1) come in contact in different types of micro-organisms. As a result of this it inhibits osteoclastic activities in root resorption and stimulate tissue repair [4]. In the recent years, a new concept has been developed, which employs the use of a combination of anti-bacterial drugs (metronidazole, ciprofloxacin and minocycline) for disinfection of pulpal and peri-radicular lesions. It has been reported that this mixture can sterilize root dentin [6]. The need for intracanal medication is greater in those cases where bacteria are resistant to routine treatment, and where the therapy cannot be successfully completed due to the presence of pain or continuing exudate[7]. Some endodontic conditions are ideally treated over several appointments which may be extended over a long period of time. This allows various medicaments to be used depending on the status of the pulp, the periapical tissues, the hard- dental tissues (such as cementum) and the condition of the apical foramen (i.e., "open", or fully developed and unaffected by resorption)[6]. The minimum inter-appointment time interval should be no less than 14 days, since inflammation takes at least 1014 days to subside or heal [8], but longer periods are generally more desirable as most medicaments take 3-4 weeks to reach their maximum concentration within the peripheral dentine. In addition, if signs or symptoms are not subsiding, then a longer period of medication time or an alternative medicament may be necessary [9].

\section{AIM OF THE STUDY}

The purpose of the study was to assess the preferences of intra-canal medicaments of Endodontists and their method of delivery into the root canal system.

\section{METHODOLOGY}

A questionnaire survey was conducted which was observational and descriptive, amongst 56
Endodontists over a period of 6 months. The questions were in an open-ended format and in English language; these were sent by Email to the survey participants. Their responses were recorded on spreadsheet and then analyzed by descriptive statistics. The questions were based on method of delivery of Intra-canal medicaments, as well as preference for these medicaments. Survey also asked the respondents about the importance of using ICMs in various endodontic conditions. Questions were also put forward that if they used different ICMs for different endodontic issues or prefer the same in all the cases.

\section{RESULTS}

While the vast majority of endodontist users in this scenario $(87.5 \%)$ chose Non-setting Calcium Hydroxide, some of them $(10 \%)$ used Formocresol (Table 2). Others used triple antibiotic paste $(2.5 \%)$. All endodontists $(100 \%)$ used ICMs in cases of necrotic pulp with periapical lesions. While considering the benefits of using ICMs in root canal therapy, endodontists were of varied opinions. A proportion of endodontists (20\%) of survey endodontists believed that ICMs provide a coronal seal but highest proportion of respondents $(53.7 \%)$ used ICMs for the disinfection of root canals whereas rest $(20 \%)$ believed that ICMs contribute to the healing of periapical lesions. It is widely accepted among endodontists that such an aim is accomplished by the elimination of infection, which can be mainly achieved using biomechanical instrumentation rather than by relying on the chemical effects of ICMs. Most respondents who used the same ICM in all cases $(85.7 \%)$ preferred non-setting Calcium Hydroxide as a primary ICM. Most respondents $(48.8 \%)$ were in the habit of using injecting syringes to insert paste-based ICMs. Maximum using injecting syringes $(48.8 \%)$, followed by Lentulo spirals $(23.8 \%)$ while others used paper points (Table 3). The former is considered a convenient and cost-effective delivery method for both patients and operators. Unlike Lentulo spirals, disposable injecting syringes are effective in terms of better cross-infection control and eliminate the need for sterilization. Lentulo spirals, due to their rotation motion, are prone to fracture with in the root canal system, especially where there is reduced corrosion resistance due to repeated sterilization cycles. Such an adverse outcome may further complicate endodontic treatment. 
Table-1: Classification of Intra- canal medicaments [4].

\begin{tabular}{|c|c|}
\hline S.No. & Classification of intra-canal medicaments (acc. To grossman) \\
\hline 1 & $\begin{array}{c}\text { Essential oils } \\
\bullet \quad \text { Eugenol }\end{array}$ \\
\hline 2 & $\begin{array}{l}\text { Phenolic compounds } \\
\text { - Phenol } \\
\text { - Parachlorophenol } \\
\text { - Camphorated parachlorophenol } \\
\text { - Cresol } \\
\text { - Crmocresol } \\
\text { - Cresatin } \\
\text { - Cresanol }\end{array}$ \\
\hline 3 & $\mathrm{~N}_{2}$ (Nitrogen) \\
\hline 4 & $\begin{array}{cl}\text { Salt of heavy metals } \\
\text { - } & \text { Metaphen } \\
\text { - } & \text { Merthiolate } \\
\text { - } & \text { Mercurophen }\end{array}$ \\
\hline 5 & $\begin{aligned} \text { Halogens } & \\
\bullet & \text { Sodium hypochlorite } \\
\bullet & \text { Iodides } \\
\text { - } & \text { Chlorexidine }\end{aligned}$ \\
\hline 6. & $\begin{array}{l}\text { Quaternary ammonium compounds } \\
\text { • 9-aminoacidine }\end{array}$ \\
\hline 7. & $\begin{array}{cc}\text { Fatty acids } \\
\qquad \quad \text { Propionic acid } \\
\text { - } & \text { Caproic acid } \\
\text { - } & \text { Cuprylic acid } \\
\end{array}$ \\
\hline 8. & Sulphonamides \\
\hline
\end{tabular}

Table-2: Preference of Intracanal medicaments (ICMs) by the survey Endodontists

\begin{tabular}{|l|l|l|l|}
\hline ICMs usage preferences & Calcium Hydroxide & Formocresol & Triple antibiotic paste \\
\hline After C\&S of vital cases & $67 \%$ & $3 \%$ & $30 \%$ \\
\hline Necrotic pulp without periapical lesion & $87.5 \%$ & $10 \%$ & $2.5 \%$ \\
\hline Necrotic pulp with periapical lesion & $73 \%$ & $15 \%$ & $12 \%$ \\
\hline Necrotic pulp with intra-oral fistula & $70.5 \%$ & $7 \%$ & $22.5 \%$ \\
\hline Failed RCTs & $89.8 \%$ & - & $10.2 \%$ \\
\hline
\end{tabular}

Table-3: Intra-canal Medicament delivery preference by Survey Endodontists

\begin{tabular}{|l|l|}
\hline ICMs delivery preferences & Percentage preference \\
\hline Paper points & $27.4 \%$ \\
\hline $\begin{array}{l}\text { Lentulo } \\
\text { spiral }\end{array}$ & $23.8 \%$ \\
\hline $\begin{array}{l}\text { Injecting } \\
\text { syringe }\end{array}$ & $48.8 \%$ \\
\hline
\end{tabular}

\section{DISCUSSION}

According to Kawashima et al. intracanal medicament is defined as temporary placement of medicaments with good biocompatibility into root canals for the purpose of inhibiting coronal invasion of bacteria. Despite conflicting claims, no medicament appears to be ideal, and significant variability exists in clinical dental practice regarding their use [10]. Intracanal medicaments in endodontics have been used for the reduction in the number of microorganisms, rendering canal content static, and prevention of post treatment pain and to improve anaesthesia. Research has shown the toxicity and probable allergenicity of the commonly used intracanal medicament particularly those of phenolic and aldehyde derivatives. With a wide choice of intracanal medicament now available selection should be made according to the special needs of the case in question. Intracanal medicament is effective in reducing the incidence of post treatment pain [11]. Use of intracanal medicament differs from case to case and person to person depending on their clinical experience. Calcium hydroxide is the most useful of all the intracanal medicaments. It has a versatile action and very effective in cases of weeping canal and open root apex. It retains its effectiveness for a long time in the root canal compared to other intra canal medicaments. Even though antibiotic has broad antimicrobial spectrum, the use of this in root canal has been controversial. One school of thought advocates the use of antibiotic in the root canal taking into consideration of topical and local action. Root canal 
medicaments are only an adjunct to root canal therapy [12]. Calcium hydroxide is one of the most commonly used intracanal medicaments and owing to the alkaline $\mathrm{pH}$, this material has a wide anti-microbial spectrum though it has some limitations in eradicating certain bacteria's in root canal [13]. Chlorhexidine gluconate (2\%) has been recommended as a potential alternative to calcium hydroxide. Formaldehyde, used as formocresol, has been used extensively in endodontic therapy despite its high toxicity and mutagenic and carcinogenic potential. Formaldehyde is volatile and releases antimicrobial vapours when applied to a cotton pellet for pulp chamber disinfection. All formaldehyde preparations are potent toxins with an antimicrobial effectiveness much lower than their toxicity [14]. Other medicaments such as Ledermix paste have been recommended as routine intracanal medicaments. It is a corticosteroid and antibiotic paste. Ledermix paste contains triamcinolone acetonide as an antiinflammatory agent [15]. Several new technologies have been introduced during the last few years to improve the effectiveness of root canal disinfection. Increasing attention has been focused on the use of ozone, photoactivated disinfection with low - energy laser, electrochemically activated water, and electric current [16]. One of the latest new developments for canal disinfection is bioactive materials such as bio (active) glass. Recent experiments with nanometric bioactive glass indicated excellent antimicrobial effect in a human dentin model. With the advent of these new technologies, the use of intracanal medicament can be surpassed; but it cannot be totally eliminated in each and every case [17]. It is important as our part to select a proper case and proper intracanal medicament for each and every patient individually, and it is very prudent to understand that irrigation and local antibacterial dressings in the root canal are part of a concerted effort to control endodontic infections. Alone they cannot guarantee success if there are problems in quality of some other parts of the treatment.

\section{CONCLUSION}

Elimination of microbial contamination from the root canal system is a prerequisite to the successful outcome of root canal treatment. The evidence shows that mechanical instrumentation, irrigation, and use of inter appointment medication were all important in this regard. However, all of the currently available antimicrobial materials for root canal irrigation and medication have limitations, and the search continues for the ideal irrigant and intra-appointment medicament.

\section{REFERENCES}

1. Kawashima, N., Wadachi, R., Suda, H., Yeng, T., \& Parashos, P. (2009). Root canal medicaments. International dental journal, 59(1), 5-11.
2. Chong, B. S., \& Ford, T. P. (1992). The role of intracanal medication in root canal treatment. International endodontic journal, 25(2), 97-106.

3. Almyroudi, A., Mackenzie, D., McHugh, S., \& Saunders, W. P. (2002). The effectiveness of various disinfectants used as endodontic intracanal medications: an in vitro study. Journal of Endodontics, 28(3), 163-167.

4. Himadri, P.A.L.(2019). Application of Intracanal Medicaments: A Review. IOSR-JDMS, 18(1):1421.

5. E Nicholas Antiseptic Medication Endodontics 3rd edition Varghese Company; 150-157.

6. Abbott, P. V. (1990). Medicaments: aids to success in endodontics. Part 1 . A review of the literature. Australian dental journal,35(5), 438448.

7. Gomes, B.P.F.A., Souza, S.F.C., Ferraz, C.C.R. (2003). Effectiveness of $2 \%$ chlorhexidine gel and calcium hydroxide against Enterococcus faecalis in bovine root dentine in vitro. Int Endod J, 36:267a275.

8. Abbott, P.V.(1990). Medicaments: Aids to success in endodontics. Part 2. Clinical recommendations. Aust Dent J, 35:491-496.

9. Jerwich, A., Figdor, D., Messer, H.(1993). pH changes in root dentin over a 4- week period following root canal dressing with calcium hydroxide. J Endod, 19:302-306.

10. Kumar, A., Tamanna, S., Iftekhar, H.(2019). Intracanal medicaments - Their use in modern endodontics: A narrative review. J Oral Res Rev, 11:89-94.

11. Lambjerg-Hansen, H., Fiehn, N.E., Krogh, P. (1982). Endodontiske medikamenter. Tandlaegebladet, 86: 467-473.

12. Estrela, C., Bammann, L.L., Pimenta, F.C., Pécora, J.D. (2001). Control of microorganism in vitro by calcium hydroxide pastes. Int Endod J, 34:416-18.

13. Siqueira, J.F., Jr., \& Lopes, H.P. (1999). Mechanisms of antimicrobial activity of calcium hydroxide: a critical review. Int Endod J, 32:361369.

14. Ellerbruch, E.S., \& Murphy, R.A.(1977). Antimicrobial activity of root canal medicament vapors. J Endod, 3:189.

15. Kumar. (2019). Intracanal Medicaments-Are their Use Advocated in Modern Endodontics: A Narrative Review. RRJDS, 7(1):14-21.

16. Balakrishna, N., Moogi, P., Kumar, G.V., Prashanth, B.R., Shetty, N.K., Rao, K.R.(2017). Effect of conventional irrigation and photoactivated disinfection on Enterococcus faecalis in root canals: An in vitro study. J Conserv Dent, 20:1258.

17. Sathorn, C., Parashos, P., Messer, H.H.(2007). How useful is root canal culturing in predicting treatment outcome? J Endod, 33:220-5. 